\title{
Fetal and Neonatal Circulatory Disorders in Twin to Twin Transfusion Syndrome (The Secondary Publication)
}

\begin{abstract}
Hitoshi Yoda
Department of Neonatology, Toho University, Faculty of Medicine, Tokyo, Japan

Twin to twin transfusion syndrome (TTTS) is a major complication of monochorionic diamniotic (MD) twins, and its onset is known to be associated with placental vascular anastomoses and blood flow imbalance. In a typical case of TTTS, the recipient develops polyhydramnios, weight gain, cardiomegaly and hydrops fetalis in the uterus. In contrast, the donor develops oligohydramnios and intrauterine growth restriction. Recently, the significance of the renin-angiotensin-aldosterone system (RAAS) that transfers from the donor to the recipient has attracted interest in the fetal circulation of TTTS. The donor has decreased renal blood flow due to decreased circulating blood volume. For this reason, the secretion of RAAS hormones is augmented in the fetal kidneys of the donor. In TTTS, these RAAS hormones from the donor transfer to the recipient through the anastomosed vessels. In addition to excess preload, the recipient heart is exposed to excess afterload due to systemic vasoconstriction through RAAS hormones. Commonly occurring complications in the recipient include myocardial hypertrophy, atrioventricular valve regurgitation, and pulmonary valve stenosis or pulmonary atresia. Fetoscopic laser photocoagulation (FLP) has been introduced recently because neither mortality nor neurological morbidity have been satisfactorily improved with conventional treatment. FLP is a curative method that may improve the prognosis of TTTS. In Japan, this procedure has been performed frequently, and positive neurological outcomes have been achieved. (J Nippon Med Sch 2019; 86: 192-200)
\end{abstract}

Key words: twin to twin transfusion syndrome (TTTS), recipient, cardiomyopathy, cardiac anomaly, fetoscopic laser photocoagulation (FLP)

\section{Pathology and Definition of TTTS}

Twin to twin transfusion syndrome (TTTS) is a complication that is observed in about 10 to $30 \%$ of monochorionic diamniotic (MD) twins ${ }^{1-3}$, and its onset is known to be associated with placental vascular anastomoses and blood flow imbalance. Twins in TTTS are commonly referred to as the recipient or the donor. In a typical case of TTTS, the recipient develops polyhydramnios, weight gain, cardiomegaly, and effusion into body cavity (hydrops fetalis) during the fetal stage and shows signs such as plethora, hypertension, polyuria, cardiomegaly, and hydrops fetalis postnatally. In contrast, the donor develops oligohydramnios and fetal growth restriction during the fetal stage and shows signs such as anemia, oliguria, renal failure, and oligohydramnios sequence postnatally.
There is, however, a broad spectrum of signs and symptoms in TTTS. Classically, TTTS was evaluated based on observing the differences in birth weight or in hemoglobin level in the neonates ${ }^{4,5}$. However, with the advances and widespread use of ultrasound examinations, TTTS is currently diagnosed by assessing the presence of twin of oligohydramnios-polyhydramnios sequence (TOPS), a condition in which monochorionic twins present an excess and deficiency of amniotic fluid during the fetal stage $^{6}$. Consequently, it has become standard practice to define TTTS as MD twins presenting abnormally large and small volumes of amniotic fluid with maximum vertical pockets of $>8 \mathrm{~cm}$ and $<2 \mathrm{~cm}$, respectively. The staging system proposed by Quintero et al. ${ }^{7}$ classifies the progression of TTTS as follows: 1) presence of amniotic fluid

Correspondence to Hitoshi Yoda, MD, Department of Neonatology, Toho University, Faculty of Medicine, 6-11-1 Omori-nishi,

Ota-ku, Tokyo 143-8541, Japan

E-mail: yoda@med.toho-u.ac.jp

https://doi.org/10.1272/jnms.JNMS.2019_86-301

Journal Website (https://www.nms.ac.jp/sh/jnms/) 
Table 1 Staging of TTTS based on sonographic and doppler findings ${ }^{5}$. Quintero RA

\begin{tabular}{cccccc}
\hline Stage & Poly/oligohydramnios* & Absent bladder in donor & CADst & Hydrops & Demise \\
\hline I & + & - & - & - & - \\
II & + & + & - & - & - \\
III & + & + & + & - & - \\
IV & + & + & + & + & - \\
V & + & + & + & + & + \\
\hline
\end{tabular}

*Polyhydramnios, MVP of $>8 \mathrm{~cm}$; oligohydramnios, MVP of $<2 \mathrm{~cm}$.

tCADs, defined as the presence of at least one of the following: (1) UA AEDV/REDV, (2) RFDV, or

(3) pulsatile umbilical venous flow (PUVF).

excess and deficiency represented by maximum vertical pockets of $>8 \mathrm{~cm}$ and $<2 \mathrm{~cm}$, respectively; 2) undetectable urinary bladder in the donor twin; 3) abnormal fetal blood flow (absence or reverse diastolic flow of the umbilical artery, pulsation waving flow of the umbilical vein, reverse diastolic flow of the ductus venosus); 4) presence of hydrops fetalis; and 5) fetal death of one of the twins (Table 1). This staging is also used to determine when to start treatment using the recentlydeveloped selective fetoscopic laser photocoagulation (FLP) to ablate placental anastomoses in the fetus and to assess the effects of such treatment ${ }^{8}$.

\section{Hemodynamics and Endocrine Environment in TTTS} Recently, the significance of the renin-angiotensinaldosterone system (RAAS) that transfers from the donor to the recipient has attracted interest in the fetal circulation of TTTS ${ }^{9}$. As described above, the recipient and donor share one placenta in TTTS, and there is a chronic transfer of blood from the donor to the recipient via vascular anastomoses. This results in a volume overload in the recipient and the opposite in the donor. Increased circulating blood volume in the recipient leads to excess preload. For this reason, there is augmented secretion of natriuretic peptides such as atrial natriuretic peptide (ANP) and B-type natriuretic peptide (BNP) and of endothelin 1 , inducing an increase in urine production ${ }^{10}$. On the other hand, the donor has decreased renal blood flow due to decreased circulating blood volume, causing a decrease in fetal urine. For this reason, the secretion of renin/angiotensin/aldosterone system, known as RAAS hormones, is augmented in the fetal kidneys of the donor. In TTTS, these RAAS hormones from the donor transfer to the recipient through the anastomosed vessels. This raises the levels of RAAS hormones in the recipient even though the recipient has an elevated circulating blood volume, and this consequently triggers a "paradoxical RAAS activation," also known as the "two- kidney one-clip" model $^{11}$. Thus, in addition to excess preload, the recipient heart is exposed to excess afterload due to systemic vasoconstriction through RAAS hormones and endothelin 1, inducing conditions such as vascular obstructive lesions, hypertension, and cardiomyopathy. Additionally, due to the effects of RAAS hormones in inducing myocardial fibrosis and thickening, the recipient may also develop a condition akin to fetal cardiomyopathy ${ }^{12}$. Such hemodynamics and the endocrine environment are considered to be the origin of the various circulatory disorders in both donor and recipient $^{13}$ (Fig. 1).

\section{Cardiovascular Complications Observed in TTTS}

The aforementioned hemodynamics reflect the various cardiac complications that arise in TTTS. In particular, the distinctive cardiac complications in the recipient are of particular interest. Cardiovascular conditions that stem from a combination of volume overload from increased circulating blood volume and pressure overload from hypertension or outflow tract impairment are the most common complications in the recipient. Highly-frequent complications include myocardial hypertrophy, atrioventricular valve regurgitation, and persistent pulmonary hypertension of the newborn, and they have been considered not to be associated with a structural anomaly ${ }^{14}$. However, there are cases in which the condition has progressed to pulmonary valve stenosis or pulmonary atresia (including functional pulmonary atresia), requiring surgical or catheter treatment in severe cases, and this, together with its etiology, has consequently attracted interest $^{15}$. Although cardiac complications are not as common in donors as in recipients, complications such as aortic coarctation are rather distinctive in donors based on the flow theory ${ }^{16}$, where there is poor aorta growth, reflecting the hemodynamics of a decreased systemic blood flow ${ }^{17}$.

It is traditionally known that twins have a greater rate 


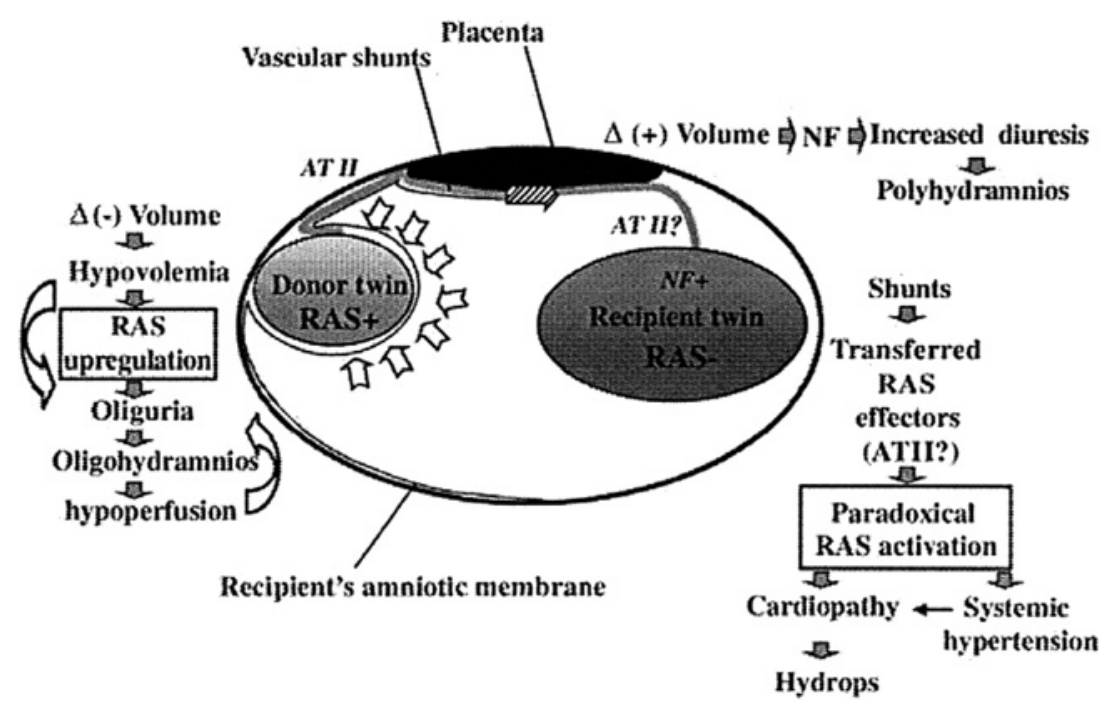

Fig. 1 Cardiac complications of the recipient:

Focusing on the intrauterine hemodynamics of the twin to twin transfusion syndrome. (RAS: renin-angiotensin system, AT II: angiotensin II, NF: natriuretic factor)

(Reprinted by courtesy of S. Karger AG, Basel from "Machiew-Caputo D, et al.: Pathogenesis of twin-twin transfusion syndrome: the renin-angiotensin system hypothesis. Fatal Diagn Ther 16; 241-244, 2001.")

of developing congenital heart diseases compared to singletons; according to a systematic review of 45 articles by Bahtiyar et al. ${ }^{18}$, the incidence was 6- to 10-fold greater in MD twins and 15- to 23-fold greater in MD twins with TTTS compared to singletons. In terms of the types of diseases, aside from ventricular septal defect that is generally observed with high frequency, right heart disorders (such as pulmonary valve stenosis and pulmonary atresia) in the recipient are notable. Although the causes of such highly-frequent cardiac complications can only be guessed, it is necessary to consider genetic factors in which a placental anomaly of twin gestation affects the fetus. In particular, the involvement of the angiogenesis factor such as vascular endothelial growth facter(VEGF), which is activated in an ischemic condition, has attracted attention $^{19}$, indicating that the hemodynamic state itself plays a key role in the onset of heart diseases in TTTS.

\section{Cardiovascular Complications Observed \\ in the Recipient}

\section{Myocardial Hypertrophy (Hypertrophic Cardio-} myopathy)

In our previous survey, myocardial hypertrophy was observed on examination in most TTTS recipients during the fetal and postnatal stages ${ }^{20}$. Others have also reported that the incidence of myocardial hypertrophy during the fetal age is high, at about $50 \%{ }^{21}$. Recently, a new TTTS fe- tal evaluation system of cardiovascular score (CV score) was proposed, where indices such as ventricular hypertrophy, cardiac dilatation, ventricular dysfunction, atrioventricular valve regurgitation, atrioventricular diastolic filling, pulmonary artery size, right ventricle outflow obstruction, pulmonary valve regurgitation, ductus venous reverse flow, and umbilical venous pulsation waveform in the recipient are measured using echocardiography in addition to umbilical artery finding in the donor $^{22}$ (Table 2). Each parameter was given a numeric value based on the degree of severity of the finding with a total maximum of 20 points. CV score was graded to four degree for severity of cardiovascular abnormality. Unlike Quintero's staging, which is largely based on donor characteristics such as abnormal blood flow, this method evaluates the recipient's cardiac complications, aiming to classify the TTTS severity with greater accuracy. In heart failure pathology that progresses from the fetal stage as described, ventricular dilatation caused by myocardial hypertrophy has been emphasized, and this is measured by the myocardial performance index (MPI, Tei index $)^{23}$. Despite their poor postnatal condition, many of these recipients with myocardial hypertrophy present with hypertension at birth. Furthermore, most recipients show cardiac dilatation with a cardiothoracic ratio (CTR) $\geq 60 \%$ on chest $X$-ray. Echocardiography shows myocardial hypertrophy that exceeds the normal myocardial 
Fetal and Neonatal Circulatory Disorders in Twin to Twin Transfusion Syndrome (The Secondary Publication)

Table 2 Cardiovascular score 22 Rychik J

\begin{tabular}{|c|c|c|c|}
\hline Variable & Parameter & Finding & Numeric score \\
\hline \multirow[t]{3}{*}{ Donor } & Umbilical artery & Normal & 0 \\
\hline & & Decreased diastolic flow & 1 \\
\hline & & absent/reversed diastolic flow & 2 \\
\hline \multirow[t]{29}{*}{ Recipient } & Ventricular hypertrophy & None & 0 \\
\hline & & Present & 1 \\
\hline & Cardiac dilatation & None & 0 \\
\hline & & Mild & 1 \\
\hline & & $>$ mild & 2 \\
\hline & Ventricular dysfunction & None & 0 \\
\hline & & Mild & 1 \\
\hline & & $>$ mild & 2 \\
\hline & Tricuspid valve regurgitation & None & 0 \\
\hline & & Mild & 1 \\
\hline & & $>$ mild & 2 \\
\hline & Mitral valve regurgitation & None & 0 \\
\hline & & Mild & 1 \\
\hline & & $>$ mild & 2 \\
\hline & Tricuspid valve inflow & Double-peak & 0 \\
\hline & & Single-peak & 1 \\
\hline & Mitral valve inflow & Double-peak & 0 \\
\hline & & Single-peak & 1 \\
\hline & Ductus venosus & All antegrade & 0 \\
\hline & & Absent diastolic flow & 1 \\
\hline & & Reverse diastolic flow & 2 \\
\hline & Umbilical vein & No pulsation & 0 \\
\hline & & Pulsation & 1 \\
\hline & Right-sided outflow tract & Pulmonary artery $>$ Aorta & 0 \\
\hline & & Pulmonary artery $=$ Aorta & 1 \\
\hline & & Pulmonary artery $<$ Aorta & 2 \\
\hline & & Right ventricle outflow obstruction & 3 \\
\hline & Pulmonary regurgitation & None & 0 \\
\hline & & Present & 1 \\
\hline
\end{tabular}

wall thickness (adjusted to body weight) by +2SD and marked tricuspid regurgitation (Fig. 2). Although the left ventricular ejection fraction is typically within the normal range, some show early stages of decreased contractile force, and myocardial hypertrophy emerges in these cases once the contractile force is improved. Myocardial hypertrophy is known to normalize in 10 days to 2 months, indicating its characteristic reversible nature ${ }^{14}$. Autopsy examination has shown a narrowing of the ventricular lumen due to thickening of the ventricular septum and posterior wall, and histopathological examination has shown distinctive myocardial hypertrophy, and in part endocardial fibroelastosis ${ }^{3,24}$. (Fig. 3)

\section{Pulmonary Artery Stenosis and Atresia (Fig. 4)}

As cardiac complications in the recipient, severe pulmonary artery stenosis and atresia do not occur as frequently as the aforementioned myocardial hypertrophy or hydrops fetalis. However, it is postulated that right ventricular outflow tract obstruction and pulmonary valve degeneration and stenosis may occur concomitantly with myocardial hypertrophy because they occur specifically in the recipient. Their severity varies, and some serious cases require pulmonary valvotomy using a balloon ${ }^{25,26}$. The authors have also treated two cases where balloon pulmonary valvotomy was required. It has been hypothesized that ${ }^{15}$ pulmonary artery stenosis develops in the TTTS recipient through an increase in systemic vascular resistance due to augmented vascular resistance in the umbilical artery, increasing the ventricular pressure, especially the right ventricular pressure. This causes right ventricular hypertrophy and tricuspid regurgitation, hindering forward ejection from the right ventricle, thereby inducing pulmonary artery stenosis and atresia. In the authors' experience, it is observed in 5\% of recipients, similar to the incidence reported by others ${ }^{27,28}$. 

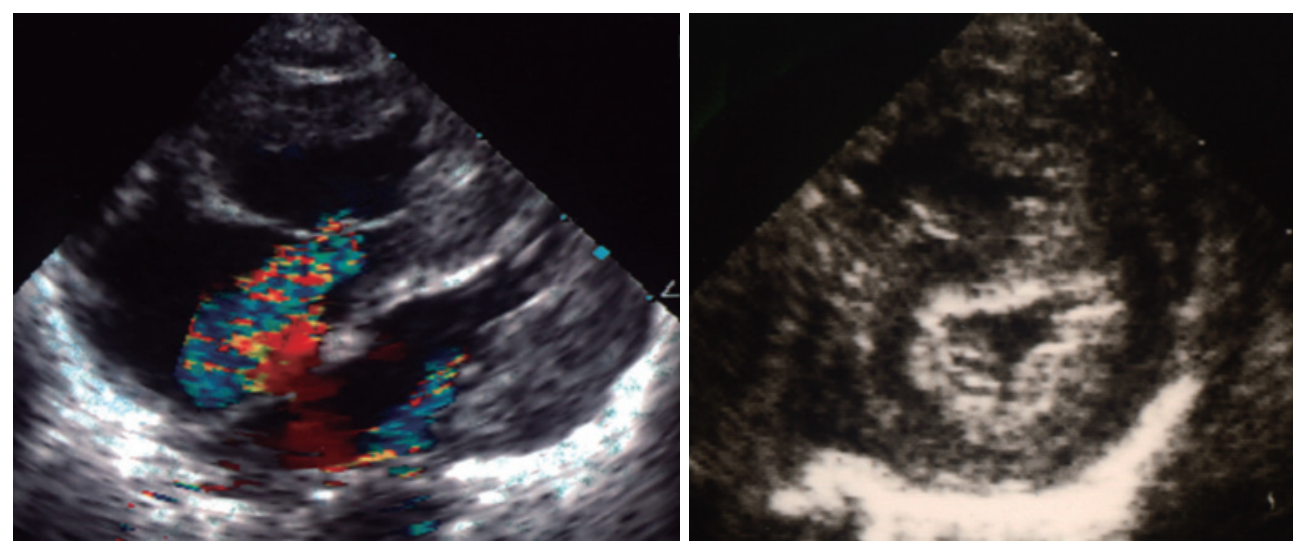

Fig. 2 Neonatal echocardiography of the recipient:

(Left) Hypertrophic cardiomyopathy with prominent tricuspid and mitral regurgitation from four chamber view. (Right) Hypertrophic cardiomyopathy from short axis view

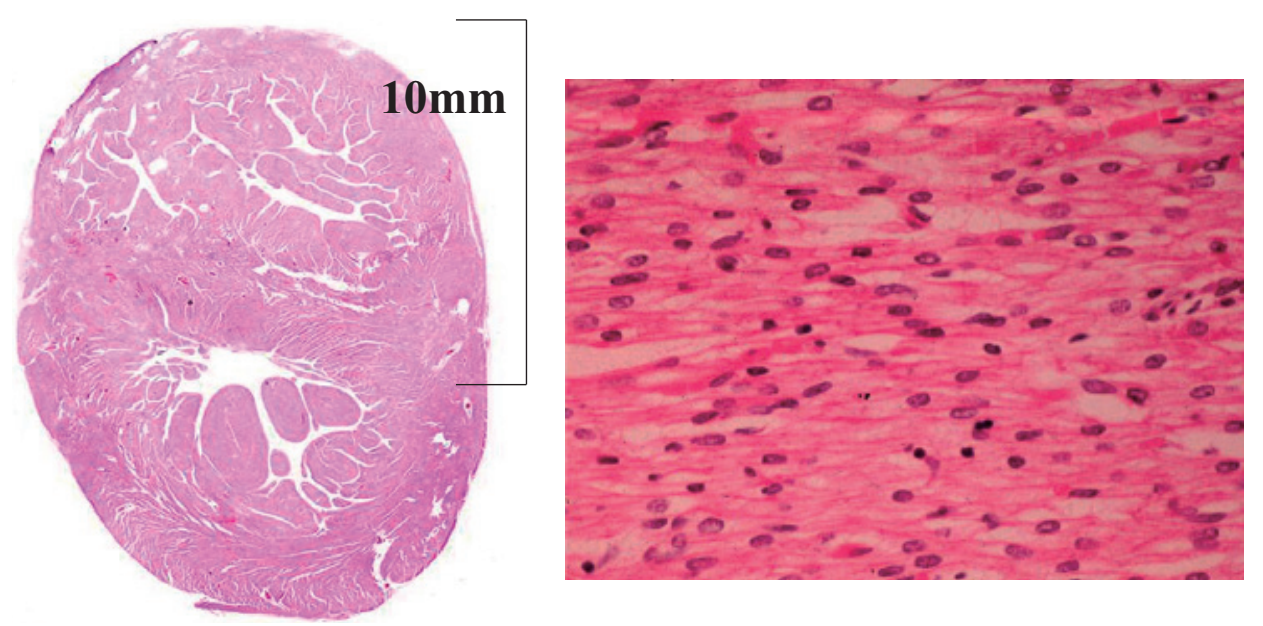

Fig. 3 The myocardial pathology of the recipient.:

(Left) The loupe image shows both of the left and the right heart chambers occupied with the myocardial hypertrophy. (Right) With the HE stain, the myocardial cells are lucid, different from the disarray formation observed with the adult hypertrophic cardiomyopathy.
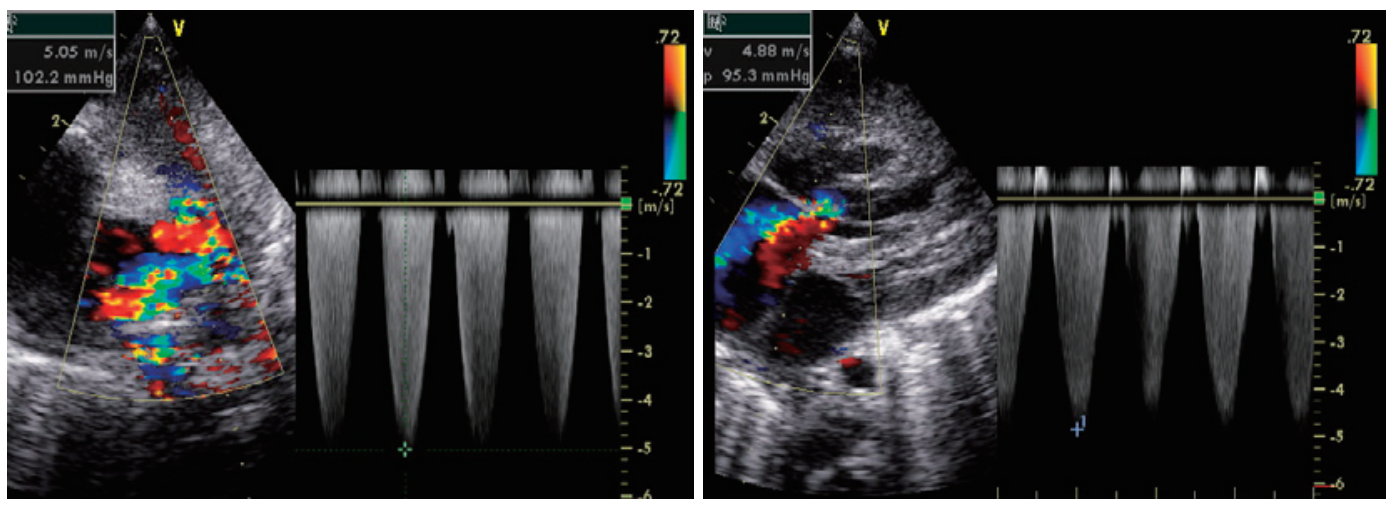

Fig. 4 Severe pulmonary artery stenosis in the recipient:

(Left) Fast pulmonary artery flow velocity (estimated $\Delta \mathrm{P}=102 \mathrm{mmHg}$ ). (Right) Tricuspid valve regurgitation Pressure gradient $\Delta \mathrm{P}=95 \mathrm{mmHg}$. 

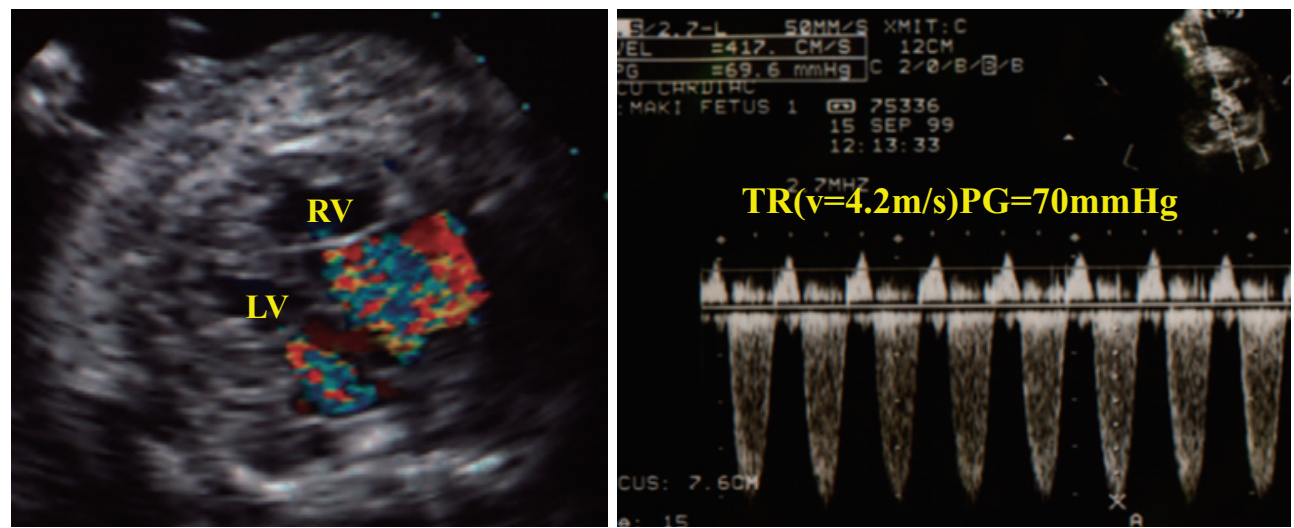

Fig. 5 A fetal echocardiography of a recipient:

(Left) Distinctive myocardinal hypertrophy is observed from the fetal stage, with atrioventricular regurgitation in the four chamber view. (Right) Tricuspid regurgitation flow measures $4.2 \mathrm{~m} / \mathrm{s}$, and with the conventional Bernoulli's formula (pressure gradient $=4 \times$ velosity $^{2}$ ), the pressure gradient between the right ventricle (RV) and the right atrium (RA) are calculated to be $70 \mathrm{mmHg}$, which means considerably high RV pressure as a fetus. It is recognized to be the cause of the recipient's fetal hydrops.
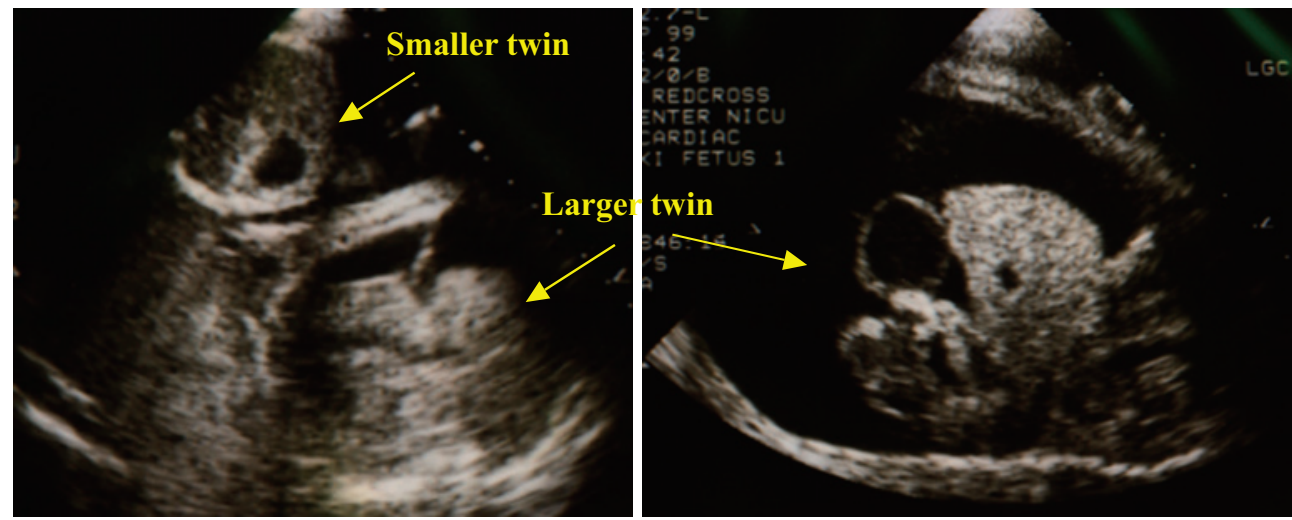

Fig. 6 A fetal sonography of a representative critical twin to twin transfusion syndrome: The polyhydroamnios of a recipient (the larger twin) and the oligohydroamnios of a donor (the smaller twin). A donor is stuck on the uterine wall and the recipient has fetal hydrops and ascites.

\section{Atrial Septal Defect}

The postulated mechanism for the onset of this condition is as follows: first, there is a synergistic effect of high-output heart failure and right ventricular outflow tract obstructive lesions in the recipient, followed by an increase in shunt via the foramen ovale, thereby having a destructive effect on the atrial septum. However, it is actually unclear whether the atrial septal defect is due to a septal tissue defect or enlargement associated with increased shunt flow ${ }^{18}$.

\section{Hydrops Fetalis}

Hydrops fetalis is observed very frequently in the recipient from the fetal stage. Fetal hypertension has been highlighted as its mechanism, and the baseline disease state is considered to involve a secondary hypertensive myocardial hypertrophy and hypertensive polyuria (polyhydramnios). In cases with atrioventricular valve regurgitation, fetal heart failure occurs, progressing to hydrops fetalis (Fig. 5) ${ }^{20}$. The signs of fetal heart failure progress from subcutaneous edema, ascites, and pericardial effusion to pleural effusion, leading to severe hydrops fetalis(Fig. 6). This condition poses a threat of intrauterine fetal death and requires neonatal treatment after delivery, although complications caused by prematurity can be lethal in markedly preterm births, creating extreme difficulties in treatment.

\section{Rare Complications}

- Left ventricular outflow tract obstruction (Fig. 7)

In marked cases of hypertrophic cardiomyopathy, left ventricular outflow tract obstruction may appear together with right ventricular outflow tract obstruction. The hemodynamics in this situation are similar to those in 

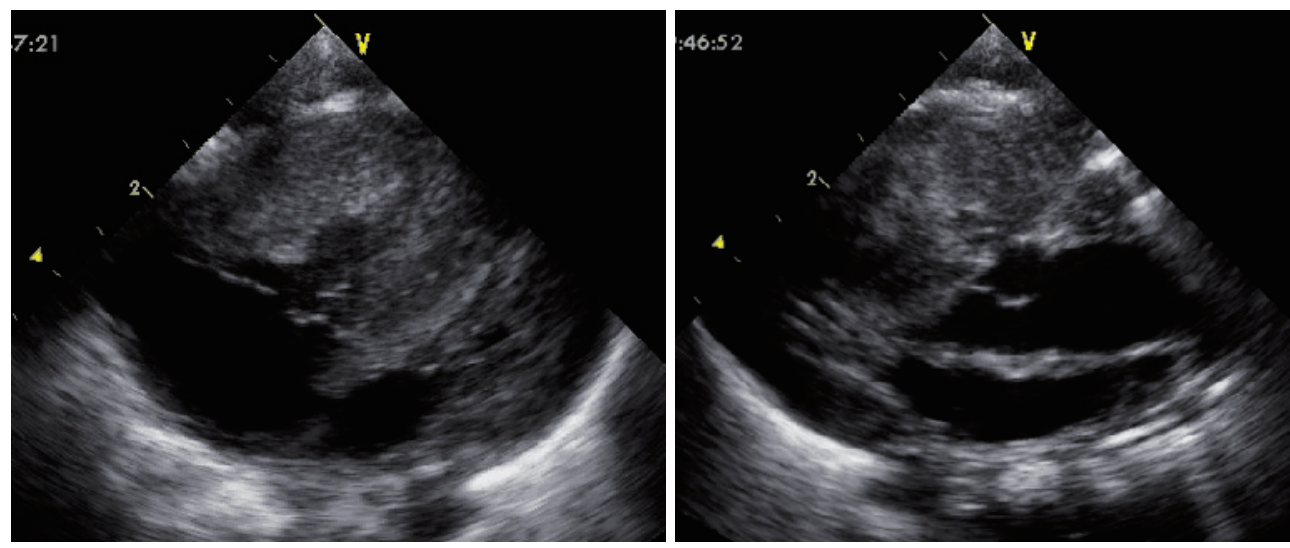

Fig. 7 Hypertrophic obstructive cardiomyopathy with left ventricular outflow tract obstruction in the recipient:

(Left) four chamber view. (Right) LV outflow view. In this case, the stenosis improves with the use of propranolol
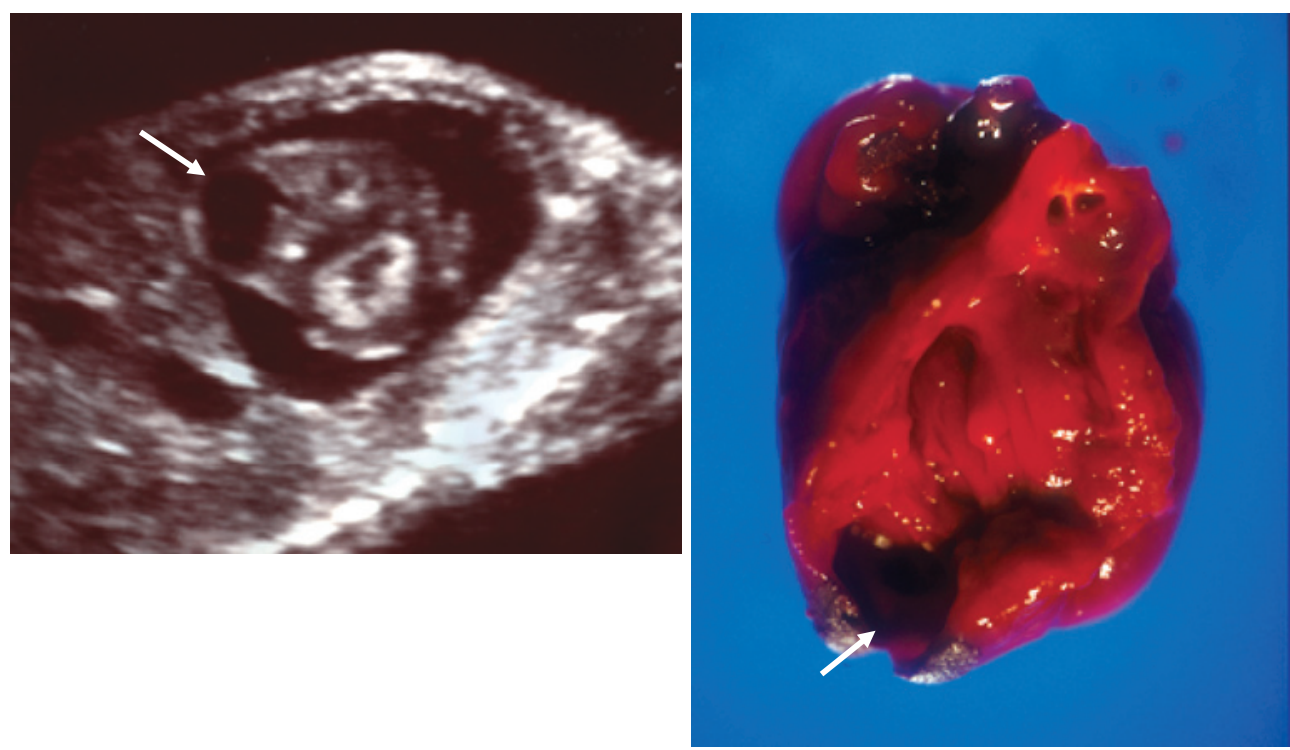

Fig. 8 Ventricular aneurysm and pericardial effusion:

(Left) A thin-walled ventricular aneurysm (arrow) that communicated with the right ventricular apex was also present. (Right) Autopsy findings showed hemorrhagic pericardial effusion and a fully-thrombosed ventricular aneurysm (arrow)

hypertrophic obstructive cardiomyopathy. In the authors' experience, with pulmonary valve stenosis, a further exacerbation in myocardial hypertrophy that is characteristic of TTTS recipients is observed because volume overload decreases after patent ductus arteriosus ligation, leading to left ventricular outflow tract obstruction. In this case, the stenosis improves with the use of propranolol $^{29}$.

- Ventricular aneurysm and pericardial effusion (Fig. 8)

In the authors' experience, bilateral lung retractions were observed in a recipient due to a large volume of pericardial effusion, and a thin-walled ventricular aneu- rysm that communicated with the right ventricular apex was also present. Autopsy findings showed hemorrhagic pericardial effusion and a fully-thrombosed ventricular aneurysm. The aneurysm histologically showed severe myocardial damage and marked fibrosis ${ }^{29}$. Although advanced myocardial ischemia has been postulated to be its trigger, a clear cause has yet to be established.

\section{Cardiovascular Complications of Fetoscopic Laser}

Photocoagulation of Placental Anastomoses (Fig. 9) Although selective FLP to treat placental anastomoses can be performed only at a limited number of institutions at the present time, it is a curative method by 

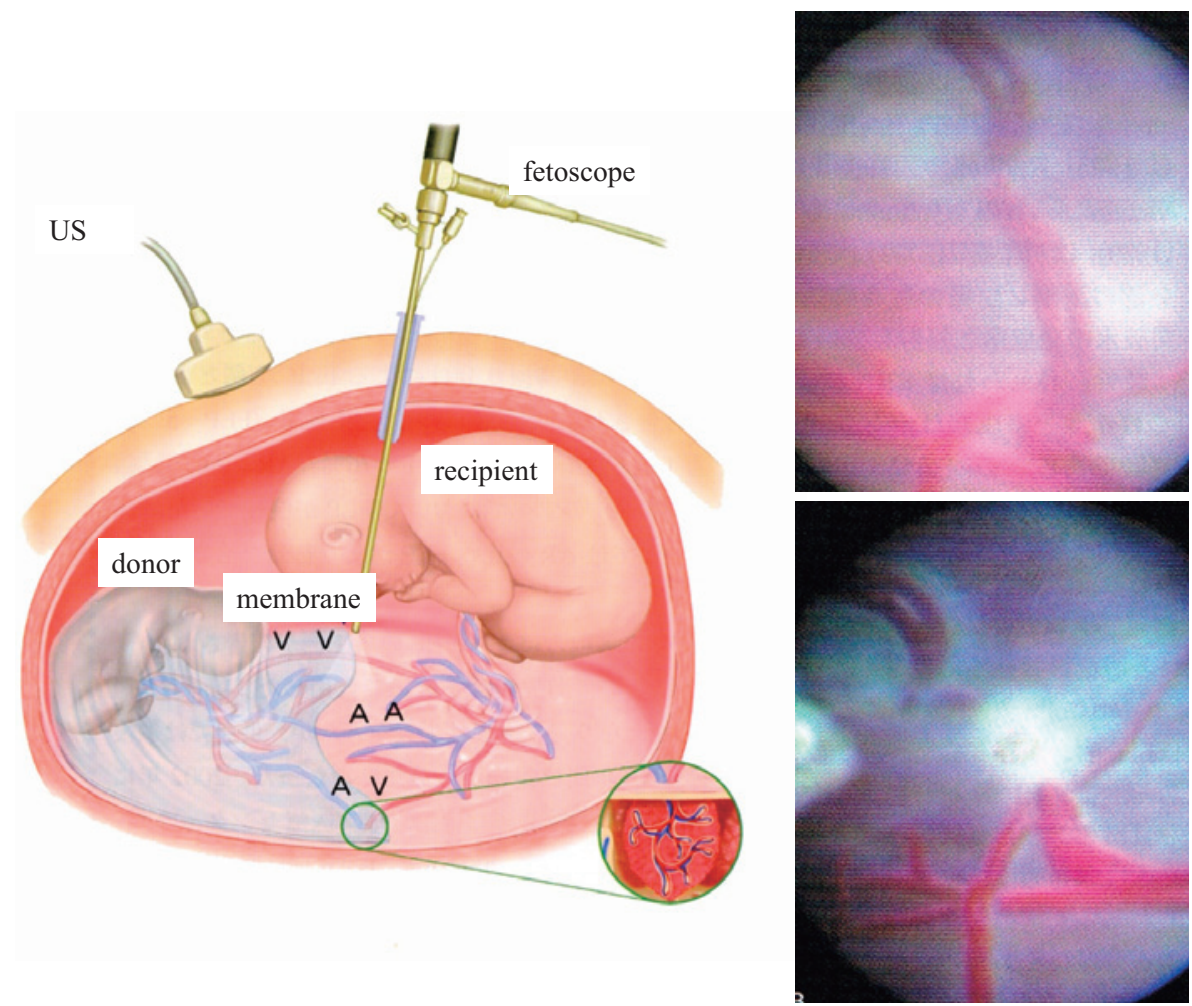

Fig. 9 Fetoscopic laser photocoagulation (FLP).:

The venous-arterial, venous-venous, and arterial-arterial vascular anastmoses are coagulated with the laser under the fetoscopy. It can be performed only in the certain medical centers, however, is a cure, treating the cause of the TTTS.

which the cause of TTTS is eliminated. It is also expected to be a therapeutic method that improves the prognosis of TTTS. In Japan, the procedure has been performed increasingly more frequently, and positive neurological outcomes have been achieved ${ }^{30,31}$. Recent reports have indicated that the aforementioned cardiovascular disorders can remain even after FLP treatment, and there are frequently observed right side cardiac anomalies in the recipient, appeared as pulmonary artery stenosis and functional atresia ${ }^{7,32,33}$. The authors have also experienced cases where functional pulmonary valve atresia developed after birth, similar to reports that described a right-side circular shunt where the ductus arteriosus flow also had a left-to-right shunt due to the presence of pulmonary artery regurgitation and tricuspid regurgitation from the fetal stage ${ }^{34,35}$. As described, cardiovascular complications can remain even after curative therapy for TTTS. These complications are similar to those observed in TTTS without fetal therapy, and the occurrence of such complications, especially right ventricular outflow tract obstructive lesions, should not be overlooked. To distinguish reversible lesions from those non-reversible is necessary, and establishment of registration system by accumulating detailed data through careful clinical practice would be the future goal to treat successfully this pathophysiology in Japan.

Editorial Comment: This article is based on a study first reported in Japanese in the Journal of the Medical Society of Toho University 2013; 60; 24-31. Because we think the content will be of great interest to J Nippon Med Sch readers, the Editorial Board requested that the authors submit it as a special review article for publication in our journal. (The content of the original Japanese article has been added to in this English version.)

Conflict of Interest: The Authors declare no conflict of interest.

\section{References}

1. Sabire NJ, Snijder RJM, Hughes K, Sepulveda W, Nicolaides KH: The hidden mortality of monochorionic twin pregnancy. Br J Obstet Gynecol 1997; 104: 1203-1207.

2. Lopriore E, Vandenbussche FP, Tieersma ES, de Beaufort AJ, de Leeuw JP: Twin-to-twin transfusion syndrome: new perspectives. J Pediatr 1995; 127: 675-680.

3. Karatza AA, Wolfenden JL, Tylor MJ, We L, Fisk NM, Gardiner HM: Influence of twin-twin transfusion syndrome on fetal cardiovascular structure and function: prospective case-control study of 136 monochorionic twin pregnancies. Heart 2002; 88: 271-277.

4. Rausen AR, Seki M, Strauss L: Twin transfusion syn- 
drome. J Pediatr 1965; 66: 613-628.

5. Tan KL, Tan SH, Tan AM: The twin transfusion syndrome: clinical observetions on 35 affected pairs. Clin Padiatr 1979; 18: 111-114.

6. Chescheir NC, Seeds JW: Polyhydramnioa and oligohydramnios in twin gestations. Obstet Gynecol 1987; 71: 882-884.

7. Quintero RA, Morales WJ, Allen MH, Bornick RN, Johnson PK, Kruger M: Staging of twin-twin transfusion syndrome. J Perinatol 1999; 19: 550-555.

8. Quintero RA, Morales WJ, Mendosa G, Allen MH, Kalter CS, Giannina G, Angel JL: Selective photocoaglation of placental vessels in twin-twin transfusion syndrome. Evolution of a surgical technique. Obste Gynecol Surv 1998; 53: s97-s103.

9. Mahieu-Caputo D, Meulemans A, Martinovic J, Gubler MC, Delezoide AL, Muller F, Madelenat P, Fisk NM, Dommergues AM: Paradoxic activation of the reninangiotensin system in twin-twin transfusion syndrome: an explanation for cardiovascular disturbances in the recipient. Pediatr Res 2005; 58: 685-688.

10. Toyoshima K, Kawataki M, Watanabe T, Itani Y, Yasui S, Nakazawa M: Clinical significance of natriuretic peptides in fetal heart disease. J Japan Ped cardiol Card Surg 2005; 21: 123-129 (in Japanese).

11. Wood JM, Gulati N, Michel JB, Hofbauer KG: Twokidney, one clip renal hypertension in the marmoset. J Hyperteinsion 1986; 4: 251-254.

12. Toyoshima K, Kawataki M, Maeno Y, Kotani M, Imai K, Matsukura T, Shibazaki J, Hosono M, Oyama M, Ishii H, Suzuki R, Nagase H, Maruyama H, Yamanaka M, Itani Y: Hemodynamics and endocrine evaluation of fetal and neonatal circulation in MDtwin. J Japan Perinat Neonat Med 2007; 43: 999-1003 (in Japanese).

13. Machiew-Caputo D, Muller F, Joly D, Gubler MC, Lebidois J, Fermont L, Dumez Y, Dommergues M: Pathogenesis of twin-twin transfusion syndrome: the reninangiotensin system hypothesis. Fetal Diagn Ther 2001; 16 241-244.

14. Yoda H, Kawakami T, Akamatsu H: Myocardial hypertrophy of Recipient in twin to twin transfusion syndromeclinical and pathological findings of seven case-. J Japan Neonat Med 1995; 31: 402-408 (in Japanese).

15. Zosmer N, Bajoria R, Weiner E, Rigby M, Vaughan J, Fisk NM: Clinical and echographic features of in utero cardiac dysfunction in the recipient twin-twin transfusion syndrome. Br Heart J 1994; 72: 74-79.

16. Rudolph AM, Heymann MA, Spitznas U: Hemodynamics considerations in the development of narrowing of the aorta. Am J Caldiol 1972; 30: 514-525.

17. Boom JVD, Battin M, Hornung T: Twin-twin transfusion syndrome, coarctation of the aorta and hypoplastic aortic arch: a case series report. J Pediatr Cild Hearth 2010; 46: 76-79.

18. Bahtiyar MO, Dulay AT, Weeks BP, Friedman AH, Copel JA: Prevalence of congenital heart defects in monochorionic/diamniotic twin gestations A systematic literature review. J Ultrasound Med 2007; 26: 1491-1498.

19. Evans PW, Wheeler T, Anthony FW, Osmond C: A longitudinal study of maternal serum vassular endthelial growth factor in early pregnancy. Hum Reprod 1998; 13: 1057-1062.

20. Yoda H, Endo D, Yamamoto W, Masumoto K, Kawakami $\mathrm{T}$, Sugimoto M: Clinical finding including cardiac function in fetus of severe twin to twin transfusion syndrome. Obstet Gynecol Practice 2004; 53: 2079-2087 (in Japanese).

21. Michelfelder E, Gottliebson W, Border W, Kinsel M, Polzin W, Livingston J, Khoury P, Crombleholme T: Early manifestations and spectrum of recipient twin cardio- myopathy in twin-twin transfusion syndrome: relation to Quintero stage. Ultrasound Obstet Gynecol 2007; 30: 965971.

22. Rychik J, Tian Z, Bebbington M, Xu F, MaCann M, Mann S, Wilson RD, Johnson MP: The twin-twin transfusion syndrome: spectrum of cardiovascular abnormality and development of a cardiovascular score to assess severity of disease. Am J Obstet Gynecol 2007; 197: 392e1-392e8.

23. Barrea C, Alkazaleh F, Ryan G, McCrindle BW, Roberts A, Bigras JL, Hornberger LK: Prenatal cardiovascular manifestations in the twin-to-twin transfusion syndrome recipients and the impact of therapeutic amnioreduction. Am J Obstet Gynecol 2005; 192: 892-902.

24. Yoda H, Nishikawa T, Takemura T, Kawakami T, Kobayashi M: Cardiac pathology in twin-twin transfusion syndrome- clinical and pathological evaluation of myocardial hypertrophy in recipients -. J Tokyo Wom Med Univ 2008; 78: 479-491 (in Japanese).

25. Seguchi M, Yamamori K, Nishio K, Yokoyama T, Iwase K, Terasawa S, Oshiro M, Inukai K, Kito H: Catheter valvotomy for severe pulmonary stenosis in very low birth weight infant. J Japan Ped Cardiol Card Surg 1996; 12: 63-67 (in Japanese)

26. Marton T, Hajdu I, Papp C, Patkos P, Hruby E, Papp Z: Pulmonary stenosis and reactive right ventricular hypertrophy in the recipient fetus as a consequence of twinto-twin. Prenat diagn 2001; 21: 452-459.

27. Lopriore E, Boekenkanp R, Rijiaarsdam M, Sueters M, Vandenbussche FP, Walther FJ: Congenital heart disease in twin-to-twin transfusion syndrome treated with fetoscopic laser surgery. Congenit Heart Dis 2007; 2: 38-43.

28. Herbeg U, Bolay J, Graeve $\mathrm{P}$, Hecher $\mathrm{K}$, Bartmann $\mathrm{P}$, Breuer J: Intertwin cardiac status at10-year follow-up after intrauterine laser coagulation therapy of severe twintwin transfusion syndrome: comparison of donor, recipient and normal values. Arch dis child Fetal Neonatal Ed 2014; 99: 380-385.

29. Yoda H: Visible sonography in twin to twin transfusion syndrome. J Pediatr Practice 2008; 71 suppl: 217-224 (in Japanese).

30. Sago H, Hayashi $S$, Saito $M$, Hsegawa $H$, Kawamoto $H$, Kato N, Nanba Y, Ito Y, Takahashi Y, Murotuki J, Nakata M, Ishii K, Murakoshi T: The outcome and prognostic factors of twin-twin transfusion syndrome following fetoscopic laser surgery. Prenat Diagn 2010; 30: 1185-1191.

31. Murotuki J, Sago H, Hayashi S, Takahashi Y, Nakata M, Ishii K, Murakoshi T: Neonatal complications after intrauterine laser coagulation therapy for twin-twin transfusion syndrome-multicenter collaborative research-. J Japan Perinat Neonat Med 2010; 46: 14-16 (in Japanese).

32. Herberg U, Gross W, Bartmann P, Banek CS, Hecher K, Breuer J: Long term cardiac follow-up severe twin-to-twin transfusion syndrome after intrauterine laser coagulation. Heart 2006; 92: 95-100.

33. Gray PH, Ward C, Chan FY: Cardiac outcome of hydrops as a result of twin-twin transfusion syndrome treated with laser surgery. J Pediatr Child Hearth 2009; 45: 48-52.

34. Pruetz JD, Chmait RH, Aklansky MS: Complete right heart flow reversal pathognotic recipient twin circular shunt in twin-twin transfusion syndrome. J Ultrasound Med 2009; 28: 1101-1106.

35. Manning N, Archer N: Cardiac Manifestations of Twin-toTwin Transfusion Syndrome. Res Hum Genet 2016; 19: 246-254.

(Received, May 30, 2017)

(Accepted, February 14, 2019) 